\title{
Učinkovitost konfuzije u suzbijanju jabukova savijača u Hrvatskoj s posebnim osvrtom na troškove zaštite
}

The efficacy of mating disruption in the control of codling moth in

Croatia, with special reference to the costs

\author{
Božena Barić, Ivana Pajač Živković
}

\section{SAŽETAK}

Istraživanje metode konfuzije jabukova savijača pomoću Isomate C TT dispenzora proizvođača SHIN ETSU® u dozi od 500 dispenzora po hektaru + 50 komada za rubno pojačanje provedeno je u voćnjaku jabuke u Nedelišću (Međimurje) 2017. godine. Metoda konfuzije primijenjena je na 2 ha voćnjaka, 1ha ispod protugradne mreže i 1 ha izvan protugradne mreže.

Ocjena učinkovitosti konfuzije i standardnog programa u kojemu je zaštita od savijača obavljena u 6 tretiranja insekticidima obavljena je u vrijeme zrelosti sorte Idared. Cijena dispenzora za konfuziju iznosila je 2.296,25 HRK, međutim gubitci jabuke iznosili s u prosjeku $2.500 \mathrm{~kg}$ ili $5.000 \mathrm{HRK}$ po hektaru. Na standardu uz 6 tretiranja insekticidima gubitak je iznosio $635 \mathrm{~kg}$ ili $1.270 \mathrm{HRK}$ po hektaru. Na netretiranoj površini gubitak je iznosio $8.500 \mathrm{~kg}$ ploda ili 17.000 HRK. Najveća učinkovitost u zaštiti od savijača postignuta je s $92,65 \%$ na standardnom dijelu voćnjaka, dok je učinkovitost na konfuziji iznosila 67,65\% i 73,53\% što nije ekonomski opravdano s obzirom na troškove zaštite i gubitke plodova prve klase. Istraživanjem je potvrđeno da se konfuzija jabukova savijača mora kombinirati s primjenom dva insekticidna tretmana koji bi povećali učinkovitost i rentabilnost proizvodnje jabuke.

Ključne riječi: Cydia pomonella, konfuzija, jabuka, suzbijanje jabukova savijača

\begin{abstract}
Investigation into mating disruption method in the control of codling moth by using Isomate C TT dispensers (SHIN ETSU $®$ ) with a dose of 500 dispensers per hectare +50 dispensers for edge reinforcement was carried out in the apple orchard Nedelišće (Međimurje) in 2017. The mating disruption method was applied on 2 hectares of orchard, 1ha below anti-hail nets and 1 ha out of the anti-hail net.
\end{abstract}


An assessment of the effectiveness of mating disruption and the standard program in which protection was carried out by applying 6 insecticides was carried out at harvest time of apple cultivar 'Idared'. The survey shows the cost of dispensers per hectare and the average price of applied insecticides, as well as the economic losses expressed in terms of yield ( $\mathrm{kg}$ of fruits) and in the national currency (HRK) per experiment variant per hectare.

The highest protection efficacy was achieved with $92.65 \%$ in the standard part of the orchard, and the efficacy on mating disruption was $67.65 \%$ and $73.53 \%$, which is not economically justified with regard to the costs of protection and first-class fruit losses. The investigation confirmed that the mating disruption method must be combined with the application of two insecticide treatments to increase the efficacy and profitability of apple production.

Key words: Cydia pomonella, mating disruption, apple, codling moth control

\section{UVOD}

Jabukov savijač (Cydia pomonella L.) ekonomski je najvažniji štetnik u svim područjima uzgoja jabuke. Zbog povoljnih klimatskih uvjeta i uzgoja jabuke kao višegodišnjeg nasada u suzbijanju jabukova savijača insekticidima potrebno je obaviti između osam i deset tretiranja. Uporabom insekticida istog mehanizma djelovanja pojavila se rezistentnost štetnika na djelatne tvari (Pajač Živković i Barić, 2017.). Velik broj tretiranja za posljedicu ima osim negativnog utjecaja na korisne organizme (Ciglar i Barić, 1996; Boller i Brown, 2000.) i zagađenje okoliša. U okviru integrirane zaštite bilja kojoj je cilj očuvanje okoliša, smanjenje unosa agrokemikalija i zdravlje ljudi, istražuju se druge ekološki povoljnije mogućnosti u suzbijanju ovog štetnika.

Prvo istraživanje primjene seksualnih feromona u zaštiti od štetnika, nakon njihova razvoja (Gaston i sur. 1967. cit. Thomson i Jenkins, 2014.) primijenjeno je u SAD-u 1978. metodom konfuzije u suzbijanju štetnika Pectinophora gossypiella (Thomson i Jenkins, 2014.). Seksualni feromoni u metodi konfuzije mogu biti alternativni način zaštite od ključnih štetnika pojedinih poljoprivrednih kultura. Njihova prednost, a ujedno i nedostatak je njihova selektivnost, te nemaju učinak na ostalu štetnu, ali isto tako niti korisnu faunu člankonožaca.

Već 1995. godine u Americi se počinje provoditi konfuzija jabukova savijača na velikim površinama i u manjim privatnim voćnjacima. Europa 
također ne zaostaje u primjeni nove tehnike (Witzgall i sur. 2008. cit. Casado i sur. 2014.). Osim prednosti, ovaj način zaštite ima i nedostatke, kao što su: troškovi rada u postavljanju dispenzora, učinkovitost ovisna o temperaturama okoliša i smjeru vjetra (pri višim temperaturama dolazi do brzog otpuštanja feromona), konfiguracija površine te visina stabala bio ograničavajući čimbenik. Zbog toga su se razvile druge tehnike u primjeni feromona kao što je uporaba aerosola s feromonom koji se automatski raspršuje u atmosferu i dostupan je na višim visinama voćnjaka (Casado i sur. 2014.). Aerosol pod nazivom PUFFER ${ }^{\circledR}$ CM primjenjuje se u mnogim zemljama u Europi i svijetu.

Poseban problem čini način ocjene učinkovitosti ove tehnike. Izostanak štete na plodovima ne mora značiti učinkovitost konfuzije, jer je moguće da populacija štetnika nije bila velika (Hoffman i Doye, 2017.). Djelovanje konfuzije procjenjuje se ulovom mužjaka na feromonske lovke unutar voćnjaka s konfuzijom. Izostanak ulova smatra se djelovanjem konfuzije. Međutim, konfuzija ne djeluje na ženke koje nesmetano mogu doći oplođene (Hoffman i Doye, 2017).

$\mathrm{U}$ Hrvatskoj metoda konfuzije pomoću dispenzora $\mathrm{s}$ feromonom nije $\mathrm{u}$ širokoj uporabi iako su prvi rezultati primjene 1999. i 2000. (Ciglar i sur. 2000.) bili obećavajući u smislu smanjenja broja tretiranja insekticidima. U prvim istraživanjima koristili su se dispenzori firme BASF pod nazivom RAK3 koji su pri višim temperaturama zraka brže hlapili te im je vijek trajanja bio kraći od potrebnog razdoblja za zaštitu jabuke u jednoj vegetaciji.

$\mathrm{Na}$ tržištu se pojavljuju dispenzori druge generacije SHIN ETSU® boljih osobina, kao što je dugotrajnije otpuštanje feromona. Istraživanja Šubića i sur. (2016.) pokazala su jednake rezultate primjenom konfuzije uz dva tretiranja insekticidima u usporedbi s redovnim programom zaštite koji je uključivao šest tretiranja insekticidima.

Konfuzija štetnika primjenom feromona unatoč dugogodišnjoj upotrebi ne daje potrebne podatke kao što su vrednovanje učinkovitosti, koja je optimalna doza dispenzora i kako postići ekonomski učinak uz visoku kakvoću plodova koju pruža zaštita insekticidima (Gut i Miller, 2017.).

Cilj ovog istraživanja bio je utvrditi učinkovitost konfuzije jabukova savijača u usporedbi sa optimalnom primjenom insekticida u suzbijanju jabukova savijača, te procijeniti troškove zaštite voćnjaka i gubitke u količini i cijeni ploda u oba načina zaštite. 


\section{MATERIJALI I METODE RADA}

Istraživanje učinkovitosti metode konfuzije u zaštiti nasada jabuke od jabukova savijača provedeno je 2017. godine u voćnjaku Agromeđimurje d. d. Čakovec u Nedelišću.

Za konfuziju jabukova savijača korišteni su dispenzori s feromonom Isomate C TT proizvođača SHIN ETSU® u dozi od 500 dispenzora po hektaru uz dodatak 50 feromona za rubno pojačanje.

Dispenzori su postavljeni 12. travnja 2017. prije početka leta jabukova savijača na 1 ha voćnjaka s protugradnom mrežom i na 1 ha bez protugradne mreže.

Radi kontrole ostavljen je lha voćnjaka bez tretiranja insekticidima na jabukova savijača.

Ostatak voćnjaka $\mathrm{s}$ protugradnom mrežom (standard) tretiran je insekticidima temeljem procjene populacije jabukova savijača pomoću feromonske lovke. U 2017. godini obavljeno je šest tretmana insekticidima.

Učinkovitost je procijenjena pregledom plodova sorte 'Idared' u vrijeme berbe 8 . rujna 2017. godine. Pregledano je po 100 plodova u 4 ponavljanja po varijanti pokusa (konfuzija pod mrežom, konfuzija izvan mreže, zaštita insekticidima pod mrežom i kontrola).

Izbor plodova za ocjenu obavljen je prema vlastitoj metodologiji potpunim obiranjem stabala u blizini rubnog dijela pokusnih površina i središnjeg dijela pokusnih površina. Svaki je plod jabuke pregledan i ocijenjen na prisutnost jabukova savijača. Rezultati pregleda statistički su obrađeni analizom varijance (F-test) i testom rangova (Duncan test).

Učinkovitost zaštite od jabukova savijača izračunata je prema Abbotu. Gubitci su u kg izračunati su pod pretpostavkom da je prosječan urod voćnjaka umanjen za prosječan postotak oštećenja po varijanti pokusa. Prema prosječnoj cijeni jabuke u berbi izračunati su gubici u Hrvatskim kunama (HRK).

Troškovi pojedine zaštite od jabukova savijača izračunati su prema cijeni primijenjenih insekticida na standardnom dijelu voćnjaka i cijeni feromona Isomate C TT. U troškove nije uračunat trošak postavljanja dispenzora, trošak rada pri aplikaciji insekticida i rad traktora.

\section{REZULTATI I RASPRAVA}

Kao što je vidljivo iz tablice 1 . najmanje napadnutih plodova bilo je na varijanti Standard $\mathrm{s}$ protugradnom mrežom i šest tretiranja insekticidima. 
Božena Barić i Ivana Pajač Živković: Učinkovitost konfuzije u suzbijanju jabukova savijača u Hrvatskoj s posebnim osvrtom na troškove zaštite

Učinkovitost primijenjene zaštite iznosila je prema Abbotu 92,65 \% (Tablica 2) a troškovi 3.741,50 HRK po hektaru, (Tablica 4). Gubitci su uz pretpostavku, prosječnog uroda ovog voćnjaka iznosili $635 \mathrm{~kg}$ po hektaru, što je s obzirom na visoku cijenu jabuke (2,00 HRK) u 2017. godini iznosilo 1.270,00 HRK po hektaru (Tablica 3).

Tablica 1. Broj napadnutih plodova jabukovim savijačem od 100 plodova po varijanti pokusa

Table 1 The number of attacked fruits by codling moth on 100 fruits per plot

\begin{tabular}{|l|c|c|}
\hline \multicolumn{1}{|c|}{$\begin{array}{c}\text { Varijanta pokusa } \\
\text { Plot }\end{array}$} & $\begin{array}{c}\text { Prosječan broj } \\
\text { Average number }\end{array}$ & Duncan test \\
\hline Konfuzija s mrežom & 5,5 & $\mathrm{bc}$ \\
C TT with net & 5.5 & $\mathrm{bc}$ \\
\hline Konfuzija bez mreže & 4,5 & $\mathrm{c}$ \\
C TT without net & 4.5 & $\mathrm{a}$ \\
\hline Standard s mrežom & 1,5 & \\
Standard with net & 1.5 & 17 \\
\hline Kontrola & 17 & \\
Control & & \\
\hline
\end{tabular}

Duncan test rangova: $\mathrm{a}>\mathrm{b}>\mathrm{c}$

Različita slova ukazuju na statistički značajne razlike na razini $1 \%$ Duncanovim testom

Duncan test of ranks: $a>b>c$

Different letters indicate significant differences at $1 \%$ level by Duncan test.

Tablica 2. Učinkovitost suzbijanja jabukova savijača prema Abbotu

Table 2 Efficacy of codling moth control by Abbot

\begin{tabular}{|c|c|}
\hline & $\begin{array}{c}\text { Učinkovitost \% } \\
\text { Efficacy \% }\end{array}$ \\
\hline Konfuzija s mrežom & 67,65 \\
C TT with net & 67.65 \\
\hline Konfuzija bez mreže & 73,53 \\
C TT without net & 73.53 \\
\hline Standard s mrežom & 92,65 \\
Standard with net & 92.65 \\
\hline
\end{tabular}


Božena Barić i Ivana Pajač Živković: Učinkovitost konfuzije u suzbijanju jabukova savijača u Hrvatskoj s posebnim osvrtom na troškove zaštite

Tablica 3. Gubitci u kg jabuke i HRK na bazi $50.000 \mathrm{~kg} / \mathrm{ha}$ i cijeni $2,00 \mathrm{HRK} / \mathrm{kg}$

Table 3 Losses in $\mathrm{kg}$ of apples and HRK based on $50,000 \mathrm{~kg} / \mathrm{ha}$ and prices of 2.00 HRK/kg

\begin{tabular}{|l|c|c|}
\hline \multicolumn{1}{|c|}{$\begin{array}{c}\text { Varijanta pokusa } \\
\text { Plot }\end{array}$} & $\begin{array}{c}\text { Gubitci u kg } \\
\text { Losses in kg }\end{array}$ & $\begin{array}{c}\text { Trošak gubitka u HRK } \\
\text { Losses in HRK }\end{array}$ \\
\hline Konfuzija s mrežom & 2.750 & 5.500 \\
C TT with net & 2,750 & 5,500 \\
\hline Konfuzija bez mreže & 2.250 & 4.500 \\
C TT without net & 2,250 & 4,500 \\
\hline Standard s mrežom & 635 & 1.270 \\
Standard with net & 635 & 1,270 \\
\hline Kontrola & 8.500 & 17.000 \\
Control & 8,500 & 17,000 \\
\hline
\end{tabular}

Tablica 4. Prosječna cijena primijenjenih insekticida u 6 tretiranja i SHIN ETSU® dispenzora po hektaru

Table 4 Average prices of six insecticide treatments and SHIN ETSU® dispensors per hectar

\begin{tabular}{|c|c|}
\hline $\begin{array}{c}\text { Insekticidi } \\
\text { Insecticides }\end{array}$ & $\begin{array}{c}\text { SHIN ETSU® dispenzori } \\
\text { SHIN ETSU® dispensors }\end{array}$ \\
\hline $3.741,50$ Hrvatskih kuna & $2.296,25$ Hrvatskih kuna \\
$3,741.50$ Croatian kunas & $2,296.25$ Croatian kunas \\
\hline
\end{tabular}

Iako se pokazala manja učinkovitost konfuzije na dijelu voćnjaka s mrežom $(67,65 \%)$ od konfuzije bez mreže $(73,53 \%)$ razlike nisu statistički opravdane. $\mathrm{Na}$ ovim varijantama pokusa nisu se koristili insekticidi u suzbijanju jabukova savijača kao niti na Kontroli. Razvidno je da je na Kontroli najveće oštećenje plodova od savijača (17\%) što iznosi gubitak od $8.500 \mathrm{~kg}$ ili 17.000,00 HRK. Međutim, smatramo da su gubitci puno veći jer je puno plodova otpalo prije zrelosti plodova kad je obavljena procjena.

Učinkovitost konfuzije koja je iznosila u našem istraživanju 67,65\% i $73,53 \%$ nije zadovoljavajuća kao jedina mjera iz razloga što je prevelik postotak oštećenih plodova (u prosjeku 4,5\% i 5,5\%), što nije rentabilno (Ciglar i sur. 2000.). Gledajući gubitke od oko 5.000 HRK ostvarene na varijanti pokusa s konfuzijom i prosječnu cijenu insekticida, pretpostavljamo da bi mogli ostvariti 
rentabilnu proizvodnju jabuke sa stanovišta zaštite od jabukova savijača mjerom konfuzije i primjenom dva tretiranja insekticidima u vrijeme masovnog leta jabukova savijača. Prema nekim istraživanjima (Gut i Miller, 2017.; Hoffman i Doye, 2017.) primjena insekticida u pravo vrijeme u voćnjaku s konfuzijom zahtijeva dodatne napore kao što je praćenje odlaganja jaja jabukova savijača prve generacije unutar voćnjaka.

\section{ZAKLJUČCI}

Istraživanje mjere konfuzije jabukova savijača s dispenzorima Isomate $\mathrm{C}$ TT SHIN ETSU® u voćnjaku jabuke u Međimurju 2017. godine, kao jedina mjera zaštite, pokazala je nedovoljnu učinkovitost zaštite plodova od savijača $(67,65 \%$ i 73,53\%) za razliku od šest tretiranja insekticidima, gdje je učinkovitost iznosila $92,65 \%$.

Gubitak zbog velikog broja oštećenih plodova od savijača na pokusnim varijantama s konfuzijom iznosio je 2.250 i $2.750 \mathrm{~kg} / \mathrm{ha}$ što je prema cijeni jabuke u Hrvatskoj u 2017. godini iznosilo gubitke od 4.500,00 i 5.500,00 HRK/ha.

S obzirom na cijenu insekticida u suzbijanju jabukova savijača koja iznosi u prosjeku $623,58 \mathrm{HRK} / \mathrm{ha}$ za jedno tretiranje i cijene dispenzora za konfuziju 2.296,25 HRK/ha možemo zaključiti da bi primjenom konfuzije uz dodatna dva tretiranja insekticidima postigli zadovoljavajuću učinkovitost i bolji ekonomski učinak.

\section{ZAHVALA}

Autori rada zahvaljuju na pomoći $u$ istraživanju voditelju voćnjaka „Nedelišće“, dipl. ing. agr. Anđelku Tomšiću, te tehnolozima u proizvodnji Dragani Bohnec, bacc. ing. i Davoru Košaku, bacc. ing. iz tvrtke Agromeđimurje d. d. Čakovec.

Istraživanje pod naslovom „Primjena bisex atraktanata $u$ praćenju i suzbijanju jabukova savijača u Međimurju“ (br. 2015-13/02) financira Vijeće za istraživanja u poljoprivredi Ministarstva za poljoprivredu RH i Međimurska županija. 
Božena Barić i Ivana Pajač Živković: Učinkovitost konfuzije u suzbijanju jabukova savijača u Hrvatskoj s posebnim osvrtom na troškove zaštite

\section{LITERATURA}

BOLLER, E.M., BROWN, W. (2000.): Functional Biodiversity and its role in Integrated fruit Production, $5^{\text {th }}$ International Conference on Integrated Fruit production, Spain, Abstract Book: 9.

CASADO, D., CAVE, F., WELTER, S. (2014).: Puffer-CM dispensers for mating disruption of codling moth: Area of influence and impacts on trap finding success by males, IOBC-WPRS Bulletin 99, 2014: 25-31

CIGLAR, I, BARIĆ, B. (1996.): Dynamic of arthropods fauna in apple orchards of North Croatia, International Conferece on Integrated Fruit Production, Buletin OILB Vol. 19(4): 128-134.

CIGLAR, I., BARIĆ, B. TOMŠIĆ, T., ŠUBIĆ, M. (2000.): Control of codling moth (Cydia pomonella) by mating disruption technique, Agronomski glasnik 1-2/2000.: 85 -93.

GUT, L., MILLER, J.R. (2017.): Mating disruption for $21^{\text {st }}$ centiry: matching technology with mechanism. IOBC-WPRS Bulletin Vol. 126:58

HOFFMANN, C., DOYE, E. (2017.): How to measure mating disruption efficacy of pheromone products for registration purpose int he field? IOBCWPRS Bulletin Vol. 126: 59-70

PAJAČ ŽIVKOVIĆ, I., BARIĆ, B. (2017.): Rezistentnost jabukova savijača na insekticidne pripravke, Glasilo biljne zaštite 5: 469-479.

ŠUBIĆ, M., BRAGGIO, A., BASSANETTI, C., ALJINOVIĆ, S., TOMŠIĆ, A., TOMŠIĆ, T. (2016).: Suzbijanje jabučnog savijača (Cydia pomonella L.) metodom konfuzije SHIN ETSU ${ }^{\circledR}$ (Isomate C/OFM i Isomate C TT+OFM rosso Flex) u Međimurju tijekom 2014, Glasilo biljne zaštite 4/2015: Vol.15/4: 277-290

THOMSON, D., JENKINS, J. (2014.): Successes with area-wide mating disruption: Moving from crisis management to sustainable pheromonebased pest management, Bulletin IOBC-WPRS, 99: 9-11. 
Božena Barić i Ivana Pajač Živković: Učinkovitost konfuzije u suzbijanju jabukova savijača u Hrvatskoj s posebnim osvrtom na troškove zaštite

\section{Adrese autora - Author's address:}

prof. dr. sc. Božena Barić,

doc. dr. sc. Ivana Pajač Živković

Agronomski fakultet Zagreb

Zavod za poljoprivrednu zoologiju

Svetošimunska 25, 10000 Zagreb 
